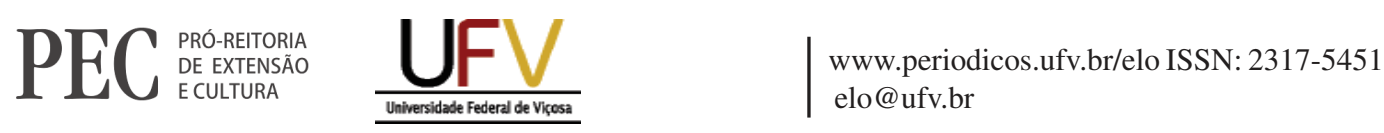

\title{
Articulação e consolidação de ações de arte e cultura no contexto universitário: a experiência do Projeto de Extensão Letras, Artes \& Mentes
}

\author{
Isa Mara Rocha Araújol, Lidiane Alves de Deus ${ }^{2}$, Monise Viana \\ Abranches ${ }^{3}$, Tiago Mendes de Oliveira ${ }^{4}$
}

\begin{abstract}
Resumo: O Projeto de Extensão Letras, Artes \& Mentes foi criado tendo em vista a realidade em que está inserida a Universidade Federal de Viçosa Campus Rio Paranaíba, localizada em uma região onde o contato com diferentes manifestações artísticas e culturais é pouco expressivo. O objetivo do projeto foi contribuir para a humanização, a sensibilização e a formação do pensamento crítico e reflexivo por meio de signos que se articulam em diferentes linguagens, bem como estimulam o desenvolvimento e o compartilhamento de habilidades e competências. Para diagnóstico e direcionamento das atividades, aplicou-se um questionário e traçou-se um cronograma, a partir dos quais implementouse espaços de leitura e fruição, instalou-se um palco, disponibilizou-se livros e revistas, realizou-se eventos e criou-se mídias sociais. O projeto promoveu articulação e consolidação de atividades de arte e cultura no contexto universitário, realizando uma efetiva construção comunitária de vivência e troca de saberes na dimensão cultural da Instituição.
\end{abstract}

Palavras-chave: Educação superior. Ambiente universitário. Políticas de extensão. Ações de arte e cultura. Desenvolvimento de habilidades e competências.

Área Temática: Cultura. Educação.

\section{Articulation and consolidation of art and culture actions in the university context: an Extension Project Letters, Arts and Minds experience}

\begin{abstract}
The University Extension Project "Literature and Languages, Arts \& Minds" was created bearing in mind the reality in which the Federal University of Viçosa - Rio Paranaiba campus, is inserted, located in a region where the contact with different artistic and cultural manifestations is not very much expressive. The aim of the project was to contribute to the humanization, awareness and formation of critical and reflective thinking through signs that articulate in different languages, as well as stimulate the development and sharing of skills and competences. To diagnose and guide the activities, a questionnaire was applied and a schedule was drawn up and, as a result, spaces for reading and enjoyment were expanded, a stage was set up, books and magazines were made available, events were held and social media was created. The project promoted the articulation and consolidation of art and cultural activities in the university context, performing an effective community construction of experience and knowledge exchange in the cultural dimension of the institution.
\end{abstract}

Keywords: Higher Education. University environment. Extension policies. Actions of art and culture. Developmentofskills andcompetences.

\footnotetext{
${ }^{1}$ Graduanda em Nutrição da Universidade Federal de Viçosa Campus Rio Paranaíba - UFV-CRP, Rio Paranaíba-MG, Brasil. Bolsista Funarbex, entre 2018 e 2019, no Projeto de Extensão Letras, Artes \& Mentes. Endereço: Rodovia MG 230, Km 07, Caixa Postal 22. Tel: (34) 3855-9362. E-mail: dxccrp@ufv.br.

${ }^{2}$ Técnica da Universidade Federal de Viçosa Campus Rio Paranaíba - UFV-CRP, Rio Paranaíba-MG, Brasil. Coordenadora do Projeto de Extensão Letras, Artes \& Mentes (PRJ-152/2018).

${ }^{3}$ Professora Doutora do curso de Nutrição e Ex-Diretora de Extensão e Cultura da Universidade Federal de Viçosa Campus Rio Paranaíba - UFV-CRP, Rio Paranaíba-MG, Brasil.

${ }^{4}$ Técnico da Universidade Federal de Viçosa Campus Rio Paranaíba - UFV-CRP, Rio Paranaíba-MG, Brasil.
} 


\section{Articulación y consolidación de acciones artísticas y culturales en el contexto universitario: la experiencia Del Proyecto de Extensión Letras, Artes y Mentes}

Resumen: El Proyecto de Extensión de Letras, Artes y Mentes fuecreado en vista de larealidad en lacual se inserta el Campus Rio Paranaíba de laUniversidad Federal de Viçosa, ubicado en una región donde el contacto con diferentes manifestaciones artísticas y culturales no es expresivo. El objetivo delproyecto era contribuir a lahumanización, sensibilización y formacióndelpensamiento crítico y reflexivo a través de signos que se articulan en diferentes idiomas, así como estimular eldesarrollo y el intercambio de habilidades y competencias. Para diagnosticar y dirigir lasactividades, se aplicóuncuestionario y se elaboróun cronograma, a partir delcual se establecieronespacios de lectura y fructificación, se creóunescenario, se pusieron a disposiciónlibros y revistas, se realizaron eventos y Secrearonlas redes sociales. El proyectopromoviólaarticulación y consolidación de actividades artísticas y culturales en el contexto universitario, realizando una construccióncomunitariaefectiva de experiencias e intercambio de conocimientos en ladimensión cultural de lainstitución.

Palabras clave: Educación superior. Ambiente universitario. Políticas de extensión. Acciones de arte y cultura. Desarrollo de habilidades y competencias.

\section{INTRODUÇÃO}

AConstituição Federal (BRASIL, 1988), em seu Art. 215, preconiza que o "Estado garantirá a todos o pleno exercício dos direitos culturais e acesso às fontes da cultura nacional, e apoiará e incentivará a valorização e a difusão das manifestações culturais". Em consonância, o Plano Nacional de Cultura (BRASIL, 2010) estabelece que todos têm direito à arte e à cultura, sendo fundamental a universalização do acesso à diversidade de manifestações.No viés da dimensão cultural, compete ao Estado promover a universalização do acesso aos meios de produção e fruição, fazendo equilibrar sua oferta e demanda, apoiando a implantação dos equipamentos e financiando a programação regular de ações culturais.

A Lei de Diretrizes e Bases da Educação Nacional - LDB (BRASIL, 1996) estabelece que a educação contempla os processos formativos que se desenvolvem na vida familiar, na convivência humana, no trabalho, nas instituições de ensino e pesquisa, nos movimentos sociais e organizações da sociedade civil e nas manifestações culturais. Nesse sentido, as universidades, como espaços educativos, de construção do conhecimento e de formação humana, abrangem a dimensão cultural, tendo o ensino superior, dentre suas finalidades, incentivar a criação e a difusão da cultura, bem como promover a extensão.

Cultura refere-se a todos os aspectos da vida em sociedade, ela é uma construção histórica, seja como conceito, seja como dimensão do processo social. Isto é, não é “algo natural”, não é uma decorrência de leis físicas ou biológicas, é um produto coletivo da vida humana, é um território atual das lutas sociais por um destino melhor, colaborando de forma efetiva para o desenvolvimento de uma sociedade e para a identidade e o sentimento de pertencimento das pessoas (BARBOSA, 1995; SANTOS, 2006).

A cultura diz respeito, ao mesmo tempo, à humanidade e a cada grupo ou indivíduo que a compõe, sendo que as diferentes culturas não sobrepõem umas às outras em grau de importância, mas tecem a teia da diversidade. Seu entendimento é uma forma de enfrentamento de preconceitos, é a base para o respeito e a dignidade das relações humanas (SANTOS, 2006). 
Nesse entendimento, a cultura é vista como um fenômeno social e humano de múltiplos sentidos. Envolve os estilos de vida, rituais, cerimônias, expressões artísticas e tecnológicas de um grupo social. É a expressão coletiva do ser humano que explica e dá sentido ao seu estar no mundo. Um processo dinâmico em permanente reconstrução, que denota o esforço para as pessoas relacionarem-se consigo e com o ambiente (CAMPO ARÁUZ, 2008).

No contexto da cultura se insere a arte, que envolve as criações humanas que expressam uma abordagem sensível, do mundo real ou da imaginação. Recorre para isso a recursos em diversas vertentes: visuais, linguísticas, sonoras, corporais. Expressa a vivência do ser humano em seu mundo, exprime ideias, sensações, emoções e percepções (BETTO, 2014).

Dentre as funções da arte destaca-se seu caráter lúdico que promove o lazer, o entretenimento e o prazer daqueles que se envolvem com a sua fruição. Assim, promove a ampliação dos horizontes e a transformação do senso estético, colaborando primordialmente para a humanização das pessoas, enquanto indivíduo e enquanto grupo. A arte traz benefícios para as pessoas, promove o desenvolvimento cognitivo, a capacidade de interpretação e contribui para a aprendizagem em todos os níveis da educação, o que pode ser aplicado, também, na esfera de atuação profissional. Além disso, desenvolve a capacidade crítica, ativando e estimulando as sensações, o potencial criativo e as emoções (ZAGONEL, 2012).

Segundo Barbosa (1995), por meio da arte, a percepção e a imaginação podem ser desenvolvidas e aprimoradas, é possível apreender a realidade do meio, desenvolver o pensamento crítico a partir de sua análise e construir, de forma criativa, alternativas para mudar o que se faz necessário. É mister refletir que, a despeito dos estratos lógico e verbal serem as formas discursivas de maior prestígio no meio acadêmico, a arte não se opõe ao conhecimento racional, ao contrário, a experiência sintetiza o entendimento e as intuições sensíveis, ou seja, ela conecta o intelecto com os sentidos e é por meio desses que aprendemos (ALVES, 2014; FELÍCIO, 1972).

Cabe ressaltar que, embora existam tantos efeitos benéficos, o restrito contato com as artes não se verifica somente nas visuais e nas cênicas, mas, também, na literatura, que é pouco apreciada pelos discentes. Essa questão vem ao encontro da tese defendida por Bamberger (2000), segundo o qual, somente 5\% das pessoas mantêm a leitura literária, ou seja, aquela que foca na fruição e na relação com a linguagem, ao longo de suas vidas. Vale lembrar que o autor é austríaco e que, no Brasil, a questão é ainda mais sensível.

Diante do exposto, a cultura e a arte nada mais são que formas de educar, elas sensibilizam os sentidos e fazem com que a ordem da utilidade e a ordem da fruição se associem, estabelecendo profundas conexões com o mundo que os cercam (ALVES, 2014). Assim, configuram-secomo caminhos para a formação, sendo complementares à educação formal e não dissonantes como se pode, a princípio, supor, e, portanto, sendo pilares para a construção de um ensino de qualidade e com formação humanística (ALVES, 2014; FELÍCIO, 1972).

Considerando-se a importância da temática, bem como o contexto em que se insere a Universidade Federal de Viçosa Campus Rio Paranaíba (UFV-CRP), localizada no interior de Minas Gerais, região do Alto Paranaíba, onde o contato com a efervescência artística e cultural dos grandes centros urbanos é pouco expressivo, 
criou-se, sob coordenação dos membros da Diretoria de Extensão e Cultura (DXC) do Campus, o Projeto de Extensão Letras, Artes \& Mentes.

A proposta se concentrou em construir caminhos que propiciassem a melhoria da conjuntura vivenciada na Instituição. Isso porque, a maioria de seus estudantes e servidores são de regiões interioranas de diferentes estados brasileiros e poucos tiveram a oportunidade, por exemplo, de assistir a uma peça de teatro, ir ao cinema, fazer uma oficina de pintura ou ouvir uma orquestra sinfônica.

Sabe-se das riquezas culturais passadas de geração em geração nas diferentes partes do Brasil, incluindo a cidade de Rio Paranaíba, que tem manifestações, como o congado, a capoeira, a folia de reis, a culinária tradicional, as músicas de viola, entre outras. Mas, aproximar diferentes expressões artísticas nesse cenário é um trabalho difícil diante da falta de um local para a troca de saberes e experiências, bem como pela escassez de recursos humanos, materiais, financeiros e, até mesmo, pela receptividade da comunidade. Entretanto, apesar de ser um desafio, faz-se necessário enaltecer a difusão cultural e artística no contexto universitário.

\section{OBJETIVOS}

Nessa ótica, o Projeto Letras, Artes \& Mentes se propôs a desenvolver estratégias para articulação e consolidação de variadas ações de arte e cultura no Campus e a aproximar a comunidade dessas múltiplas manifestações, sendo seu principal objetivo contribuir para a humanização, a sensibilização e a formação do pensamento crítico e reflexivo, por meio de expressões artísticas e culturais que se articulam em diferentes linguagens, bem como estimulam o desenvolvimento e compartilhamento de habilidades e competências, neste âmbito, entre os membros da comunidade acadêmica e extra-acadêmica.

Diante disso, foram adotados alguns objetivos específicos, a saber: (a) Criar e manter espaços de leitura, aprendizagem, fruição estética e trocas de saberes; (b) Desenvolver estratégias metodológicas visando a aproximação e fruição artística com emprego de diversas linguagens; (c) Realizar campanhas para obtenção de recursos materiais para desenvolvimento do projeto; (d) Compreender como as manifestações culturais afetam a vida das pessoas; (e) Contribuir para a aprendizagem da Língua Portuguesa, por meio de expressões artísticas que se articulam com diferentes gêneros textuais e estimular o desenvolvimento de habilidades e competências linguísticas entre os discentes e demais membros da comunidade acadêmica; (f) Desenvolver e manter uma mídia digital visando divulgar os relatos das experiências vivenciadas, bem como sugestões de eventos e obras; (g) Divulgar as atividades em congressos e em periódicos da área.

\section{METODOLOGIA}

O Projeto de Extensão Letras, Artes \& Mentes, registrado no Sistema de Registro de Atividades de Extensão - RAEX (BRASIL, 2019) sob o n ${ }^{\circ}$ PRJ-152/2018, foi desenvolvido entre 01 de agosto de 2017 e 30 de junho de 2019, pelos servidores da Diretoria de Extensão e Cultura e por discentes do Campus; incluindo, no 
período de 01 de outubro de 2018 a 30 de junho de 2019, uma bolsista do Programa Funarbe de Apoio à Extensão - Funarbex/UFV (BRASIL, 2018).

Para diagnóstico e direcionamento das atividades desenvolvidas, bem como para identificação de pontos importantes sobre a percepção da comunidade quanto a temática do Projeto e a obtenção do contato de pessoas com habilidades e competências artísticas, aplicou-se um questionário online, composto de questões objetivas e discursivas.A partir das informações obtidas pela compilação dos dados, considerou-se necessário criar e manter espaços de leitura, aprendizagem, fruição e troca de saberes e traçar um cronograma de atividades visando a aproximação da comunidade a diferentes expressões artísticas e culturais.

Na UFV Campus Rio Paranaíba, os eventos educacionais, de ensino, pesquisa e extensão, como os simpósios, as semanas acadêmicas, as exposições e as apresentações culturais e artísticas, são realizadas nos saguões do Pavilhão de Aulas (PVA) e da Biblioteca, nos Auditórios do Prédio dos Laboratórios de Ensino (LAE) e no salão de eventos do Restaurante Universitário (RU). Esses espaços são dedicados à realização de eventos diversos da Instituição, e embora sejam amplos, não possuem como missão precípua a difusão cultural e artística. Nesse sentido, considerando a importância que deve ser dada aos eventos dessa natureza, foi criado o “Espaço Letras \& Mentes” e instalado um palco, ambos no Pavilhão de Aulas (PVA) da Universidade, os quais se caracterizaram como ambientes para efetivação dos objetivos do Projeto.

O Espaço Letras \& Mentes foi estruturado de forma a acolher e ser um lugar propício para a imersão cultural, tanto para a comunidade acadêmica quanto para a extra-acadêmica. Neste ambiente foram inseridas mesas, cadeiras, quadro, giz, pufes, entre outros objetos e decorações de caráter educativo, para a realização das ações. Também, a instalação de um palco no Pavilhão de Aulas (PVA) foi outro mecanismo pensado para fortalecer e incentivar as atividades culturais e artísticas na Instituição, sendo de uso compartilhado e aberto, ampliando o acesso e a participação da comunidade.

Além disso, nos locais, foram disponibilizados, aproximadamente, 550 exemplares de livros e revistas de forma gratuita, livre e irrestrita, colaborando para uma maior articulação literária na Instituição. Cabe ressaltar que essa ação contou com a colaboração da própria comunidade universitária, bem como de diversas editoras públicas e privadas que em resposta a uma campanha de doação de livros do projeto, forneceram os exemplares.

Diante dos espaços criados, as atividades propostas no cronograma, buscaram agradar o maior número de público possível, sendo planejadas exposições, recitais, campanhas, oficinas, lançamentos, rodas de conversa, festivais, apresentações artísticas, feiras e movimentos. As ações foram desenvolvidas, em sua maioria, pelos próprios membros da comunidade acadêmica, que gentilmente se prontificaram a compartilhar seus talentos, e também por membros da sociedade de Rio Paranaíba e região, que cordialmente atenderam nosso convite.

Os equipamentos e materiais utilizados nas atividades foram, de certo modo, fatores limitantes, demandando criatividade dos membros do Projeto, uma vez que não havia uma fonte específica de recursos disponível para sua aquisição.Desse modo, algumas das atividades precisaram ser repensadas para se adequarem à realidade 
física e financeira da DXC e da UFV Campus Rio Paranaíba. Nesse sentido, para as ações serem realizadas, recorreu-se ao empréstimo de equipamentos, como, por exemplo, microfones, caixas de som e pedestais e também à contribuição financeira daprópria DXC e da Diretoria Geral do Campus. Os materiais de papelaria para a confecção de cartazes, banners, folders e murais foram conseguidos também por meio da contribuição da Instituição, que sempre incentivou as atividades.

Ademais, como estratégia de aproximação e diálogo com a comunidade acadêmica e extra-acadêmica, criou-se os perfis do Projeto e da DXC em uma mídia social, possibilitando a divulgação das atividades, bem como a articulação e publicação de diferentes gêneros textuais, especialmente, poesia.

Nesse contexto e frente ao planejamento elaborado, o Projeto foi conduzido de modo a envolver a comunidade nas atividades, proporcionando vivência de novas experiências e desenvolvimento e compartilhamento de habilidades.

\section{RESULTADOS E DISCUSSÃO}

O questionário elaborado para diagnóstico da conjuntura do tema arte e cultura na comunidade acadêmica e extra-acadêmica recebeu respostas de 113 participantes, distribuídos entre discentes $(64,6 \%)$, docentes $(24,8 \%)$, técnico-administrativos $(8,8 \%)$ e comunidade externa $(1,8 \%)$.

Constatou-se, em relação ao grau de importância dada as ações artísticas e culturais, que a maioria dos respondentes considera importante ou muito importante ( $85 \%$ ) ações de arte e cultura em seu dia a dia, como música, dança, teatro, rodas de conversa, oficina e exposições, indicando a relevância atribuída à temática no cotidiano da comunidade.

A pergunta “O que o motiva a participar de atividades culturais e artísticas?", fez emergir respostas que contemplavam palavras como interesse, alegria, gosto, descontração, entretenimento, deleite e prazer. Elas demonstraram a associação entre arte e cultura com sensações agradáveis e com o despertar de emoções consideradas positivas. Vale ressaltar três destas respostas: "Me alegra, me descansa e dá esperança." (sic); “Essas atividades são terapias para mente." ( ic e "Melhora na saúde mental e as possibilidades de novos encontros e oportunidades." (sic).

Também, diversos respondentes abordaram temas como conhecimento, aprendizado, formação cultural, curiosidade, diversidade e valorização das tradições, como pode ser observado nos seguintes trechos: "Conhecer novas ideias e pensamentos, estimular a criatividade, trabalhar com o lado emocional.” (sic); "Acredito que a interação com cultura e arte ajudam as pessoas crescerem de formas que não somos ensinados em escola ou faculdade." (sic); "Resgatar o passado, não ignorar as origens e vivê-las." (sic) "Valorizar a cultura de nosso país, as características do nosso povo e a expressão disso.” (sic).

Essas respostas vão ao encontro das proposições de Alves (2014), que compara a educação a um "grande brinquedo" que desafia a inteligência dos alunos e os faz pensar e trabalhar para decifrar enigmas. Mas, 
que ao mesmo tempo, confere prazer quando os põe à prova e testa suas habilidades e é isso que faz o corpo sonhar e se movimentar.

Ressalta-se assim a relevância de projetos e eventos que abordam a formação artística e cultural das pessoas e colaboram para uma formação holística no contexto universitário, ambiente esse, muitas vezes, focado tão somente na formação técnica.

Quanto as ações que despertam maior interesse do público, conforme apresentado no Gráfico 01, destacaram-se música e artes visuais, as quais foram escolhidas por 85 e 69 pessoas que responderam ao questionário, representando, respectivamente, $75,2 \%$ e $61,1 \%$ das respostas.

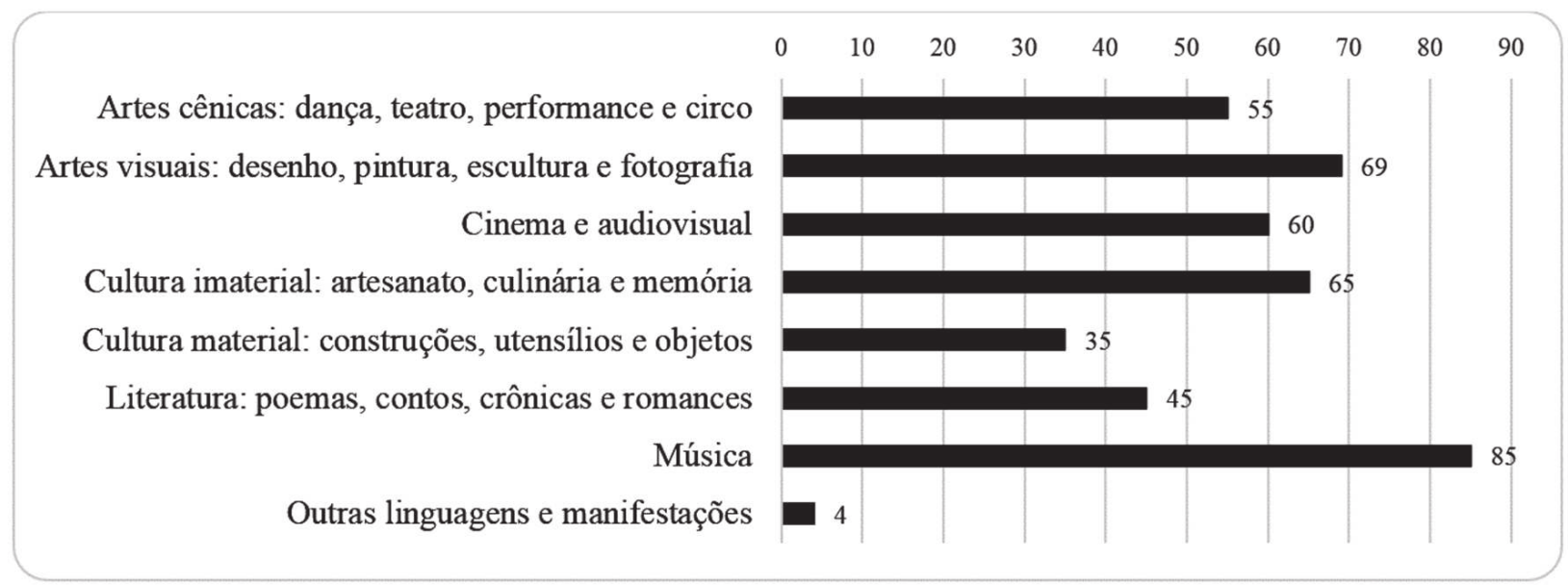

Gráfico 01 -Atividades artísticas e culturais que despertaram maior interesse.

Fonte: Elaborado pelos autores conforme dados da pesquisa (2018).

O conhecimento das atividades consideradas de maior interesse para o público, bem como o levantamento do contato de pessoas com habilidades artísticas e culturais (49 nomes com talentos em diversas áreas), mediante o questionário, possibilitaram a realização de diversos eventos, como exposições, apresentações artísticas, festivais, campanhas, saraus, oficinas e minicursos que contribuíram para a fruição artística e cultural dos participantes, bem como para o estímulo e motivação das pessoas em desenvolverem e/ ou compartilharem habilidades e competências. O Quadro 01 apresenta as 34 atividades realizadas no período e vinculadas ao Projeto.

Ademais, foram realizadas oficinas de arte e artesanato, no contexto do Simpósio de Integração Acadêmica (SIA). Na edição de 2018, foi incorporado ao SIA do Campus Rio Paranaíba o I SIACULT Mostra Cultural UFV/CRP, que contou com apresentações artísticas, bem como, com os seguintes minicursos: macramê, bordado com sianinha, desenho realista com lápis grafite, filtro dos sonhos, diferentes tipos de pátinas e pinturas em latas. 
Quadro 01 - Atividades realizadas pelo Projeto de Extensão Letras, Artes \& Mentes.

\begin{tabular}{|c|c|c|c|}
\hline $\mathbf{N}^{0}$ Registro & Título & Início & Término \\
\hline EVE-2094/2017 & $\begin{array}{l}\text { Exposição de Fotografias e Documentos: Pensar o Passado, Projetar o Futuro: } \\
\text { UFV } 91 \text { Anos - Fazemos Parte desta História }\end{array}$ & $16 / 08 / 17$ & $01 / 09 / 17$ \\
\hline EVE-2080/2017 & Recital de Música de Câmara Erudita e Popular & $24 / 10 / 17$ & $24 / 10 / 17$ \\
\hline EVE-2274/2017 & Exposição: Consciência Negra - Orgulho, Força e Resistência. & $23 / 11 / 17$ & $24 / 11 / 17$ \\
\hline EVE-2387/2019 & I Campanha de Doação de Livros & $26 / 02 / 18$ & $30 / 03 / 18$ \\
\hline EVE-688/2018 & $\begin{array}{l}\text { Cerimônia de Inauguração do Espaço Letras \& Mentes e Apresentação } \\
\text { Musical com Camila Rocha e Marcos Pereira }\end{array}$ & $22 / 03 / 18$ & $22 / 03 / 18$ \\
\hline CUR-144/2018 & Oficina de Desenho Realista & $23 / 03 / 18$ & $23 / 03 / 18$ \\
\hline EVE-687/2018 & Oficina de Colorização e Matização de Cores & $23 / 03 / 18$ & $23 / 03 / 18$ \\
\hline EVE-1410/2018 & $\begin{array}{l}\text { Lançamento do Livro Minhas Histórias de Trancoso e Contação de } \\
\text { Histórias - Primeira Seção }\end{array}$ & $17 / 04 / 18$ & $17 / 04 / 18$ \\
\hline EVE-1402/2018 & $\begin{array}{l}\text { Lançamento do Livro Minhas Histórias de Trancoso e Contação de Histórias } \\
\text { - Segunda Seção }\end{array}$ & $17 / 04 / 18$ & $17 / 04 / 18$ \\
\hline EVE-1424/2018 & Exposição Imagética e Literária - Trabalho: Arte e Sobrevivência & $23 / 04 / 18$ & $11 / 05 / 18$ \\
\hline EVE-1411/2018 & Oficina de Aquarela & $15 / 06 / 18$ & $15 / 06 / 18$ \\
\hline EVE-1426/2018 & $\begin{array}{l}\text { Exposição Imagética e Literária - Das Árvores às Florestas, das Folhas } \\
\text { aos Versos }\end{array}$ & $13 / 08 / 18$ & $24 / 08 / 18$ \\
\hline EVE-1698/2018 & Exposição APAExonad@s por arte & $27 / 08 / 18$ & $06 / 09 / 18$ \\
\hline EVE-2017/2018 & SIACult 2018 - Mostra Cultural UFV/CRP & $15 / 10 / 18$ & $18 / 1018$ \\
\hline EVE-1958/2018 & Exposição Queijo Minas Artesanal: Patrimônio Cultural Brasileiro. & $15 / 10 / 18$ & $26 / 10 / 18$ \\
\hline EVE-2548/2018 & (R)existências - SIACult & $15 / 10 / 18$ & $15 / 10 / 18$ \\
\hline EVE-2168/2018 & Roda de Conversa: Café, queijo e prosa & $16 / 10 / 18$ & $16 / 10 / 18$ \\
\hline EVE-1959/2018 & Exposição fotográfica: Cores do Cerrado - Rio Paranaíba & $18 / 10 / 18$ & $18 / 10 / 18$ \\
\hline EVE-2351/2018 & Momento Paisagístico na Fotografia & $26 / 11 / 18$ & $07 / 12 / 18$ \\
\hline EVE-2388/2019 & II Campanha de Doação de Livros & $28 / 02 / 19$ & $29 / 03 / 19$ \\
\hline EVE-2392/2019 & Festival Cultural de Boas-Vindas 2019 & $12 / 03 / 19$ & $15 / 03 / 19$ \\
\hline EVE-3334/2019 & Exposição em Mesas: Ação Gera Motivação & $12 / 03 / 19$ & $22 / 03 / 19$ \\
\hline EVE-3337/2019 & Exposição Fotográfica: Conheça sua Universidade, Conheça seu Campus & $12 / 03 / 19$ & $22 / 03 / 19$ \\
\hline EVE-3336/2019 & Exposição Interativa: O Universo Conspira a Nosso Favor & $12 / 03 / 19$ & $15 / 03 / 19$ \\
\hline EVE-2686/2019 & Exposição de Desenhos Realistas & $08 / 04 / 19$ & $17 / 04 / 19$ \\
\hline EVE-2683/2019 & Momento Paisagístico na Fotografia (Prefeitura Municipal Rio Paranaíba) & $22 / 04 / 19$ & $29 / 04 / 19$ \\
\hline EVE-2915/2019 & Exposição do Humor & $13 / 05 / 19$ & $17 / 05 / 19$ \\
\hline EVE-2909/2019 & Quarta-feira da Cultura da UFV Campus Rio Paranaíba & $22 / 05 / 19$ & $22 / 05 / 19$ \\
\hline EVE-2913/2019 & Oficina de Pintura em Tela & $22 / 05 / 19$ & $22 / 05 / 19$ \\
\hline EVE-2912/2019 & I Feira do Livro & $22 / 05 / 19$ & $22 / 05 / 19$ \\
\hline EVE-3018/2019 & Exposição de Aglomerados Urbanos e Rurais & $03 / 06 / 19$ & $07 / 06 / 19$ \\
\hline EVE-3017/2019 & Closet Compartilhado - Movimento DesaPegue & $11 / 06 / 19$ & $19 / 06 / 19$ \\
\hline EVE-3016/2019 & Oficina de Pintura em Aquarela & $12 / 06 / 19$ & $12 / 06 / 19$ \\
\hline EVE-3265/2019 & Arraiá da UFV-CRP & $28 / 06 / 19$ & $28 / 06 / 19$ \\
\hline
\end{tabular}

Fonte: Elaborado pelos autores, conforme dados do RAEX (BRASIL, 2019). 
As ações que ocorreram, principalmente, no Espaço Letras \& Mentes e no palco do PVA(FIGURA 01), promoveram momentos de encontro para a troca de saberes, a vivência de novas experiências em diferentes aspectos (intelectual, social, econômico, lazer) e culminaram no desenvolvimento de novas habilidades e competências entre os participantes.
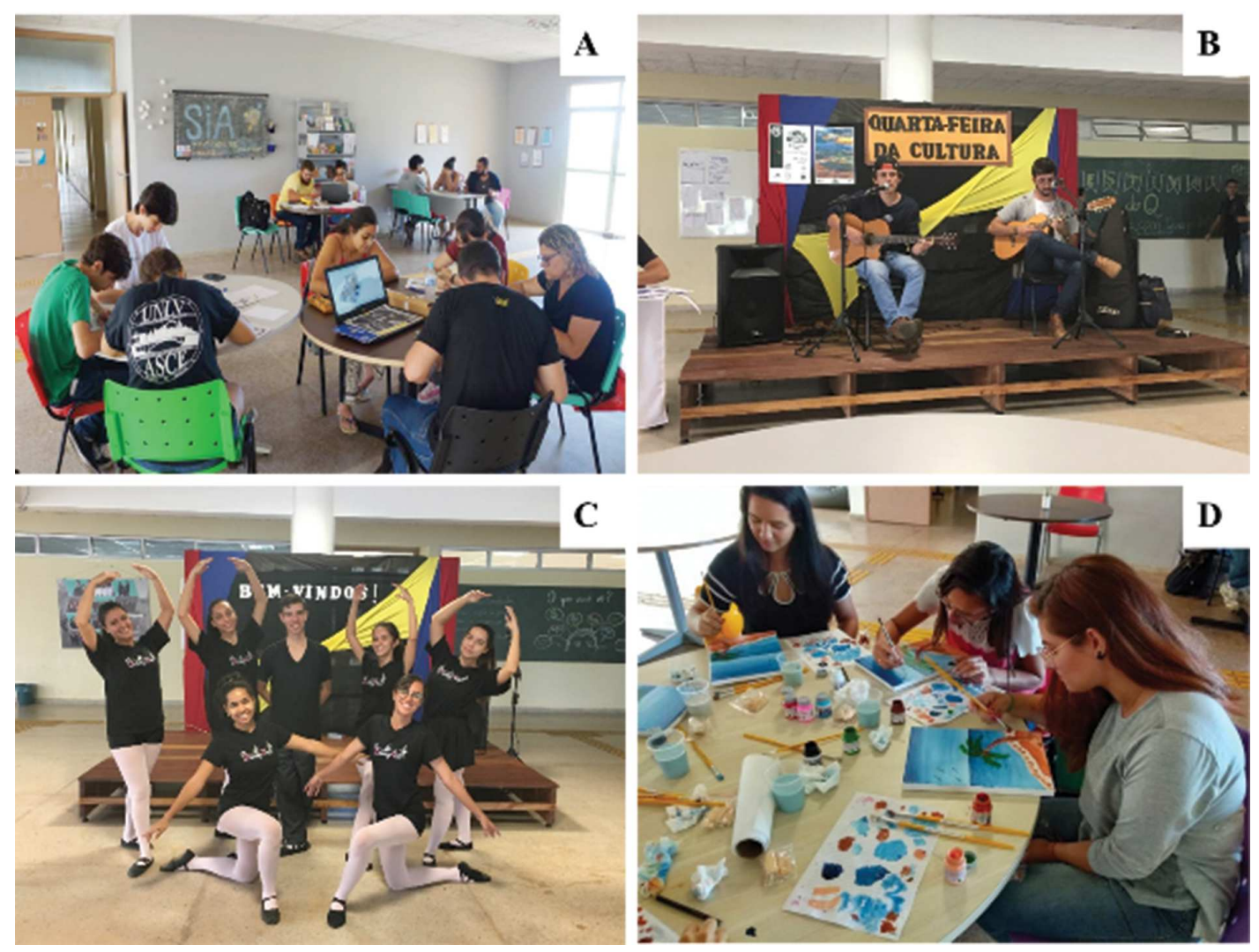

Figura 01 - Ações realizadas pelo Projeto de Extensão Letras, Artes \& Mentes. A) Minicurso de Desenho Realista, no Espaço Letras \& Mentes; B) Apresentação musical, no palco do PVA; C) Apresentação de balé do Grupo DançArt, no saguão do PVA; D) Minicurso de pintura em tela, no Espaço Letras \& Mentes.

Fonte: Comissão coordenadora do projeto.

Com o intuito de incentivar a leitura, as campanhas de doação de livros literários e revistas, resultaram no recebimento de cerca de 480 obras doadas pela comunidade e de cerca de 70 de livros novos disponibilizados por editoras públicas e privadas, que também compactuaram com a ação solidária, totalizando aproximadamente 550 exemplares. Essas parcerias propiciaram a construção de um rico acervo, o qual, de forma livre, gratuita e irrestrita, colabora na ampliação da cultura no Campus.

Cabe destacar que a possibilidade de uso coletivo dos exemplares, tem estimulado, entre os discentes e os servidores, o despertar para a leitura e a ampliação do olhar para questões antes não pensadas, incluindo a indicação, por eles, de textos considerados interessantes.

Outro ponto que vale destacar, são os resultados advindos da criação dos perfis do Projeto e da DXC em uma mídia social, nos quais foram divulgadas todas as atividades propostas pelo Letras, Artes \& Mentes. 
Alcançou-se mais de 1600 pessoas, como seguidores dos perfis projetolam e $d x c \_u f v \_c r p$, além do acesso aberto, o qual não é possível mensurar.

Ressalta-se que além de ferramentas essenciais para a divulgação das atividades, os perfis possibilitaram a articulação de diferentes gêneros textuais, uma vez que foram publicados poemas, poesias e frases de autores como Carolina Maria de Jesus, Machado de Assis, Manoel de Barros, Manuel Bandeira e Rubem Alves. Vale frisar que os textos foram selecionados pelos membros do Projeto, tomando-se o cuidado em usar referências confiáveis, para evitar a circulação de conteúdo com erros e falsas autorias, fato, infelizmente, comum na internet.

Essa ação colaborou para a ampliação da bagagem cultural dos leitores que interagiram com o Projeto por meio das mídiase, além disso, somou aos membros da equipe que se dedicaram à leitura e à seleção dos textos que foram disponibilizados, vivenciando momentos de aprendizado e fruição literária.

A divulgação dos fragmentos nas mídias sociais obteve reverberação dos internautas-leitores, através de "curtidas" e também de comentários, como na postagem de um trecho do livro Quarto de Despejo de Carolina Maria de Jesus (1960): "Parabéns, belíssima reflexão, Carolina Maria de Jesus é uma autora extraordinária que ainda não tem o seu merecido reconhecimento, lindo ver isso aqui”. ( $\mathrm{sic}$ )

Diante da experiência relatada, percebeu-se que as atividades desenvolvidas proporcionaram maior aproximação a expressões artísticas e culturais, momentos de encontro para troca de saberes, desenvolvimento e compartilhamento de habilidades e competências e novas vivências em diferentes aspectos como intelectual, social, econômico e de lazer.

Assim, acredita-se que o Projeto em questão seja também um instrumento de promoção da humanização. Segundo Freire (1979), humanizar é se comprometer com o mundo, com os próprios homens, é ter responsabilidade para com estes e a história. Comprometer-se é a prática de agir e refletir sobre a realidade, e este ato só é válido se for cerceado de humanismo, o qual faz com que a pessoa/profissional, busque se aperfeiçoar, procure ampliar seus conhecimentos sobre o homem e sua forma de ser sobre o mundo.

Ademais, a receptividade do Projeto pôde ser verificada pela adesão aos eventos e pelo feedback positivo recebido durante e após as atividades, com relatos de aprovação e pedidos para que novas ações fossem realizadas. Apesar das dificuldades e do pouco acesso à arte e à cultura na região, a equipe do Projeto verificou que há interesse e demanda pela temática.

\section{CONCLUSÕES}

Arealização do Projeto de Extensão Letras, Artes \& Mentes na Universidade Federal de Viçosa Campus Rio Paranaíba promoveu articulação e consolidação de atividades de arte e cultura no contexto universitário, realizando uma efetiva construção comunitária de vivência e troca de saberes na dimensão cultural da Instituição, sendo expressiva a receptividade e o envolvimento da comunidade nas ações realizadas. 
Nesse sentido, o Projeto colaborou com o incentivo, criação e difusão da cultura, aspectos reconhecidamente importantes na construção do conhecimento e na formação humana, condizendo com a Carta Magna, que em seu Artigo $215^{\circ}$ preconiza que a cultura é uma necessidade básica e direito de todos os brasileiros.

Sabe-se que ainda há um vasto caminho a ser percorrido no que diz respeito à concretização e valorização das manifestações artísticas e culturais, entretanto, a experiência no contexto da extensão universitária, demonstrou que esse tipo de ação contribui expressivamente para a humanização e sensibilização dos envolvidos.

No que tange ao aspecto ético e cultural, tais atividades demonstram-se muito relevantes, pois o contato com diferentes manifestações, as trocas de saberes, o compartilhamento e o desenvolvimento de novas habilidades e competências ampliaram a formação dos envolvidos possibilitando maior senso crítico, reflexivo e de coletividade, frente à realidade em que estão inseridos.

Importante ressaltar que muitas das ações foram institucionalizadas como atividades, espaços e práticas regulares na Instituição. Eventos de diversas naturezas, principalmente de cunho cultural são realizados no "Espaço Letras \& Mentes", bem como no palco instalado na Universidade; doações de livros acontecem com frequência, mesmo em períodos em que não há campanhas específicas para este fim e as mídias sociais estão a cada dia com mais adeptos, sendo um excelente canal de difusão de ações envolvendo expressões artísticas e culturais.

Espera-se que em médio prazo os participantes, especialmente o corpo discente, se aproxime ainda mais de diferentes linguagens artísticas e culturais, incluindo a leitura. Também, é esperado que o Projeto fomente outras atividades na mesma linha de atuação, coordenadas por outros servidores.

\section{AGRADECIMENTOS}

Os autores do trabalho agradecem a Universidade Federal de Viçosa e a Fundação Arthur Bernardes, face ao Programa Funarbe de Apoio à Extensão Universitária (FUNARBEX), pela concessão de bolsa, à aluna de graduação membro do projeto, no âmbito do Edital 03/2018 e às editoras Edições Câmara, Edufac, EDUFBA, Editora UFPR, Editora UnB, Jangada, Objetiva e Vivara que gentilmente realizaram a doação de livros para comporem o acervo do projeto.

Agradecem também aos estudantes e servidores da UFV-CRP e a comunidade extra-acadêmica que compartilharam de suas habilidades, realizando apresentações, minicursos, oficinas e demais eventos, possibilitando a realização do Projeto e Extensão Letras, Artes \& Mentes.

\section{REFERÊNCIAS}

ALVES, Rubem. Educação dos sentidos e mais... 10 ed. Campinas, SP: Verus Editora, 2014.

BAMBERGER, Richard. Como incentivar o hábito de leitura. 7. ed. Trad. Octavio M. Cajado. São Paulo: Ática, 2000. 
BARBOSA, Ana Mae Tavares Bastos. Educação e Desenvolvimento, Cultural e Artístico. In: Educação \& Realidade, vol. 20, nº 2, jul./dez. 1995, p. 9-17. Disponível em: <https://seer.ufrgs.br/educacaoerealidade/ article/view/71713/40662>. Acesso em: 08 ago. 2019.

BETTO, Janete Maria. O Ensino de Arte e a Educação do Sensível. Curitiba/PR: Secretaria de Educação, 2014. Os Desafios da Escola Pública Paranaense da Perspectiva do Professor Produções DidáticoPedagógicas, Volume II. Disponível em: <http://www.diaadiaeducacao.pr.gov.br/portals/cadernospde/ pdebusca/producoes_pd e/2014/2014_unicentro_arte_pdp_janete_maria_betto.pdf $>$. Acesso em: 09 ago. 2019.

BRASIL. Constituição da República Federativa do Brasil de 1988. Disponível em: <http:// www.planalto.gov.br/ccivil_03/constituicao/constituicao.htm>. Acesso em: 05 ago. 2019.

BRASIL. Lei $\mathrm{n}^{\circ}$ 12.343, de 2 de dezembro de 2010. Institui o Plano Nacional de Cultura - PNC, cria o Sistema Nacional de Informações e Indicadores Culturais - SNIIC e dá outras providências. Disponível em: <http://www.planalto.gov.br/ccivil_03/_ato2007-2010/2010/lei/112343.htm>. Acesso em: 05 ago. 2019.

BRASIL. Lei n ${ }^{\circ}$ 9.394, de 20 de dezembro de 1996. Estabelece as diretrizes e bases da educação nacional. Disponível em: <http://www.planalto.gov.br/ccivil_03/leis/19394.htm>. Acesso em: 05 ago. 2019.

BRASIL. Universidade Federal de Viçosa. RAEX-Sistema de Registro de Atividades de Extensão. Disponível em: <http://www.raex.ufv.br>. Acesso em: 19 ago. 2019.

BRASIL. Universidade Federal de Viçosa. Programa FUNARBE de Apoio à Extensão - FUNARBEX 2018-2019. Disponível em: <http://www.pec.ufv.br/?page_id=352>. Acesso em: 19 ago. 2019.

CAMPO ARÁUZ, Lorena. Diccionario básico de Antropología. Quito/Ecuador: Abya-Yala; Quito/ Ecuador: Universidad Politécnica Salesiana, 2008. Disponível em: <https://www.cpalsocial.org/documentos/ 776.pdf>. Acesso em: 09 ago. 2019.

FELÍCIO, Vera Lúcia. Filosofia em Nova Chave. Discurso, São Paulo, v. 3 n. 3, 1972. Disponível em: <http:/ /www.revistas.usp.br/discurso/article/view/37748/40475/>. Acesso em: 14 ago. 2019.

FREIRE, Paulo. Educação e Mudança. 12.ed. Rio de Janeiro: Paz e Terra, 1979.

JESUS, Carolina Maria de. Quarto de Despejo: Diário de uma Favelada. $1^{\text {a }}$ edição. Rio de Janeiro: Francisco Alves, 1960.

SANTOS, José Luiz dos. O que é cultura. São Paulo: Brasiliense, 2006.

ZAGONEL, Bernadete. Arte na educação escolar. Curitiba: InterSaberes, 2012. Coleção Metodologia do Ensino de Artes.

Submetido em: 17/09/2019 Aceito em: 08/10/2019. 